\title{
ANÁLISE FILOGENÉTICA MORFOLOGICA DA FAMÍLIA TYPHLOTANAIDAE SIEG, 1984 (TANAIDACEA, TANAIDOMORPHA)
}

\author{
Segadilha, J.L. ${ }^{1,}$; Błażewicz, M. ${ }^{2} \&$ Serejo, C.S. ${ }^{1}$ \\ ${ }^{1}$ Departamento de Invertebrados, Laboratório de Carcinologia, Museu Nacional (MN/RJ), \\ Quinta da Boa Vista s/n, ${ }^{20940-040 ~ R i o ~ d e ~ J a n e i r o, ~ R J, ~ B r a s i l . ~}$ \\ ${ }^{2}$ Department of Invertebrate Zoology and Hydrobiology, University of Łódź, Banacha ${ }^{12 / 1} 6$, $90-{ }^{23} 7$ Łódź, Poland. \\ *Autor correspondente: julianasegadilha@gmail.com
}

\begin{abstract}
A família Typhlotanaidae ocorre em todos os oceanos e possui distribuição batimétrica da zona do entremarés até $5000 \mathrm{~m}$ de profundidade. Typhlotanaidae foi analisada neste trabalho através de métodos cladísticos com base em caracteres morfológicos externos. A análise foi realizada utilizando o programa TNT a partir de uma matriz de caracteres compreendendo 128 caracteres, sendo 65 modificados a partir da bibliografia e 63 estabelecidos no presente estudo x 87 táxons terminais (81 espécies do grupo-interno e 6 do grupo-externo). O material incluído na análise representando os 13 gêneros conhecidos para a família foi proveniente do material-tipo e não-tipo de coleções européias e informações da literatura. Além disso, dados da plataforma continental e talude brasileiros foram incluídos, onde foi possível a descrição de Aremus brasilica e ainda outras sete espécies novas que estão sendo descritas. As análises foram feitas por busca tradicional com 8000 réplicas e 500 árvores mantidas por réplica. Foram realizadas duas análises, uma com pesos iguais, resultando em 144 árvores mais parcimoniosas ( $\mathrm{L}=1161$ passos, $\mathrm{Cl}=0,15$ e $\mathrm{RI}=0,50)$, sendo realizada posteriormente uma árvore de consensu strito; e uma segunda análise com pesos implicados $\mathrm{K}=10,455 ;$ Fit=38,513, resultando em uma árvore mais parcimoniosa ( $\mathrm{L}=1189$ passos, $\mathrm{Cl}=0,15$ e $\mathrm{RI}=0,49$ ). A família Typhlotanaidae se apresentou como monofilética em ambas as análises, com 1 sinapomorfia não homoplástica e 5 sinapomorfias homoplásticas na de pesos implicados; e 2 não homoplásticas e 2 homoplásticas na de pesos iguais. Os gêneros Antiplotanais, Obesutanais, Paratyphlotanais, Peraeospinosus, Pulcherella e Typhlamia permaneceram monofiléticos, assim como o gênero Aremus descrito a partir deste trabalho, os quais foram recuperados em ambas as análises. Além disso, o complexo de espécies Typhlotanais 'trispinosus' (T. trispinosus, T. tenuicornis, T. trispinosus sp. nov. 1, T. trispinosus sp. nov. 2) foi recuperado nas duas árvores, sendo possivelmente um gênero novo com três caracteres diagnósticos apomórficos. Larsenotanais mostrou-se monofilético somente na árvore de consensu; em contraposição a Hamatipeda que apareceu monofilético apenas na análise com pesos implicados. Torquella e Meromonakantha se apresentaram como parafiléticos em ambas as análises. Esta é a primeira análise evolutiva da família com abordagem morfológica e traz grandes reflexões sobre as relações intra-específicas e entre os gêneros de Typhlotanaidae.
\end{abstract}

Palavras-chave: análise cladística, filogenia, caracteres morfológicos, Paratanaoidea, Brasil. 